\title{
Solvent extraction of iron (III) from chloride acid solutions by decanol
}

\section{Xuehua Mao}

College of Biological and Chemical Engineering, Panzhihua University, Panzhihua 617000, Sichuan, China

chdmaoxh@sina.com

Keywords: decanol; iron; solvent extraction; $\mathrm{HCl}$.

Abstract The solvent extraction of iron (III) from acidic chloride solutions by decanol in kerosene has been investigated. The solvent extraction results demonstrated that the dissolved iron was present as $\mathrm{HFeCl}_{4}$.2Decanol. Extraction of iron (III) increased with increased hydrochloric acid concentration in the aqueous phase. On the other hand, titanium (IV ) aluminum (III), calcium (II) and magnesium (II) were not extracted under these experimental conditions. IR spectral study of the extracted complex was further used to clarify the nature of the extracted complex. The extracted complex was easy to strip. Using $0,0.5$ and $1 \mathrm{~mol} . \mathrm{dm}^{-3} \mathrm{HCl}$ as the stripping agents the stripping rate of iron (III) was above $90 \%$.

\section{Introduction}

Nowadays, solvent extraction is widely used for the separation and recovery of valuable metals from industrial streams. The investigation on the solvent extraction of iron (III) mainly focused on separation of iron from blue dust, iron scrap, waste chloride pickle liquors from steel plants and ilmenite leach liquors. A survey of the literature showed that a large number of reagents had been used for the extraction of iron (III), such as organophosphorus acid derivatives ${ }^{[1-7]}$, amines ${ }^{[8-11]}$, neutral extractants ${ }^{[12-15]}$, carboxylic acid etc. Among them, organophosphorus acid extractants and amines are the leading extractants for iron (III) in acid solutions. Iron (III) extraction with di (2-ethylhexyl) phosphoric acid $\left(\mathrm{D}_{2} \mathrm{EHPA}\right)$ has been extensively studied. In the extraction, difficulties have been reported in stripping the loaded organic when $\mathrm{D}_{2}$ EHPA was used as the extractant. A high concentration of acid is required to strip iron (III) from the acidic extractant, and the selectivity is poor.

The simultaneous extraction of micro and macro amounts of $\mathrm{In}, \mathrm{Fe}, \mathrm{Ga}, \mathrm{Cd}, \mathrm{Co}$ and $\mathrm{Zn}$ from $\mathrm{HCl}$ medium using Tri-n-octylamine (TOA) and Aliquat 336 in benzene as extractant showed a decrease in extraction of microelements in presence of the extractable of macroelements ${ }^{[8]}$. For Fe with TOA the extracted complex was TOAHFeCl$l_{4}$; with Aliquot 336 the extracted complex was $\mathrm{R}_{4} \mathrm{NFeCl}_{4}$. Miroslav $\mathrm{M}$ al reported the extraction of $\mathrm{Fe}$ (III) from $\mathrm{HCl}$ medium with Tri-n-octylamine in benzene, xylene, toluene, chloroform, carbon tetrachloride and cyclohexane ${ }^{[16]}$. The study concluded that the formation of cyclic polymer complexes of structures had the ratio of TOA: $\mathrm{HCl}: \mathrm{FeCl}_{3}$ as 2:2:1 in extractions carried out at low acid concentrations that changed to 1:1:1 for extractions carried out at higher acid concentrations. Lee MS al conducted solvent extraction experiments of $\mathrm{FeCl}_{3}$ in $\mathrm{HCl}$ solution with Alamine336 as an extractant. Solvent extraction reaction depended on the ratio of initial concentration of Alamine 336 to $\mathrm{FeCl}_{3}$. When the concentration of Alamine 336 was in excess to that of $\mathrm{FeCl}_{3}$, the extractant reacted as a dimer. When the initial concentration ratio of Alamine 336 to $\mathrm{FeCl}_{3}$ was below three, ferric chloride was extracted by monomeric extractant.

In the extraction of iron (III) with amines, the important problem is the appearance of the third phase. Yu S al reported synergistic extraction of ferric iron in sulfate solutions by a tertiary amine and 2-ethylhexyl 2-ethylhexyl phosphonic acid (HEHEHP) or dialkyl phosphonic acid ${ }^{[1]}$. It has been indicated that with the addition of tertiary amine not only are the rates of extraction and stripping increased but also the concentration of sulfuric acid required for the stripping of iron in the organic phase is reduced. The synergistic extraction of N235-TBP for iron (III) in sulfate solutions was studied ${ }^{[17]}$. The addition of TBP eliminated the third phase and that the extraction rate of iron (III) was improved. Mishra RK al reported solvent extraction of Fe (III) from the chloride leach 
liquor of low-grade iron ore tailings using Aliquat 336 in kerosene. Nonylphenol was used as the third phase modifier ${ }^{[9]}$. Zhou XX al reported the effects of modifiers on the extraction of cobalt (II) and iron (II) with a tertiary amine. It was found that the addition of modifiers, oxygen-containing organic compound and hexanol both could eliminate the third phase ${ }^{[18]}$. But the mechanism didn't be covered. And the extraction of alcoholic solvents for iron (III) have not been reported.

To explore the extraction performance of alcoholic solvents for iron (III) in acid chloride solutions and provide basis for the eliminate of the third phase in amines extraction for iron (III), a detailed investigation to the solvent extraction and stripping behavior of iron (III) in the hydrochloric acid solutions by decanol was carried out in the present study.

\section{Experimental}

\section{Reagents and apparatus}

Iron (III) solution was prepared from $\mathrm{FeCl}_{3}$ by diluting to the required concentration with hydrochloric acid. Other mental ion solutions were prepared by dissolving their salts in hydrochloric acid and diluting to the required concentration with distilled water. Decanol (98\%) was procured from AODA Chemical Co., Ltd. (Luoyang, Henan, China). Kerosene was kindly supplied by Sichuan MAX-TOP petrochemical science and technology Ltd. All other chemicals used were of analytical reagent grade.

Apparatus: A 721 UV-visible spectrophotometer and a Nicolet 6700 IR spectrophotometer were employed.

\section{Extraction and analytical procedures}

Solvent extraction and stripping experiments were carried out by shaking required volumes of aqueous and organic phases at an O/A phase radio of 1 for 10 minutes at $298 \pm 1 \mathrm{~K}$. After phase separation, the concentration of the specific mental ion remaining in the aqueous phase was determined by standard procedures. Thus, iron (III), titanium (IV ), aluminum (III), magnesium (II) and Calcium (II) were analyzed spectrophotometrically using respectively 1,10-phenanthroline, hydrogen peroxide, Eriochrome Cyanine R, Eriochrome black-T and ACBK. The concentration of the mental ion in the organic phase was attained by mass balance.

\section{Results and discussion}

\section{Extraction equilibria}

To explore the extraction mechanism of decanol for iron (III) in chloride acid solutions, the following investigation was carried out.

The effect of decanol concentration on the extraction of iron (III) has been studied in $8 \mathrm{~mol} \mathrm{dm}^{-3}$ hydrochloric acid (Fig 1). The result showed that the extraction of iron (III) increases with increased decanol concentration. From the slope of $\log \mathrm{D}$ versus $\log$ [Decanol], it can be inferred that two molecules of decanol are involved in the extracted complex of iron (III).

The effect of chloride ion concentration $\left(4 \sim 7 \mathrm{~mol} \mathrm{dm}^{-3}\right)$ on the extraction of iron (III) with 0.86 mol dm${ }^{-3}$ decanol in kerosene was investigated at a given hydrogen ion concentration $\left(4 \mathrm{~mol} \mathrm{dm}^{-3}\right)$ using $\mathrm{HCl}+\mathrm{CaCl}_{2}$ mixtures (Fig 2). It is clear from the result that the extraction of iron (III) increases with increase in chloride concentration in the aqueous phase. The $\log \mathrm{D}$ versus $\log \left[\mathrm{Cl}^{-}\right]$ plots gave slopes of 4.0 in the case of iron (III), indicating the involvement of four chloride ions in the extracted complex of iron (III).

The extraction behavior of iron (III) with $0.86 \mathrm{~mol} \mathrm{dm}^{-3}$ decanol in kerosene was investigated as a function of hydrogen ion concentration $\left(4 \sim 8 \mathrm{~mol} \mathrm{dm}^{-3}\right)$ at a given chloride ion concentration $(8 \mathrm{~mol}$ $\mathrm{dm}^{-3}$ ) using $\mathrm{HCl}+\mathrm{CaCl}_{2}$ mixtures (Fig 3). The result showed that the extraction of iron (III) increases with increase in hydrogen ion concentration in the aqueous phase. The $\log \mathrm{D}$ versus $\log$ $\left[\mathrm{H}^{+}\right]$plots gave slopes of 1 in the case of iron (III), indicating the involvement of one hydrogen ion in the extracted complex of iron (III). 


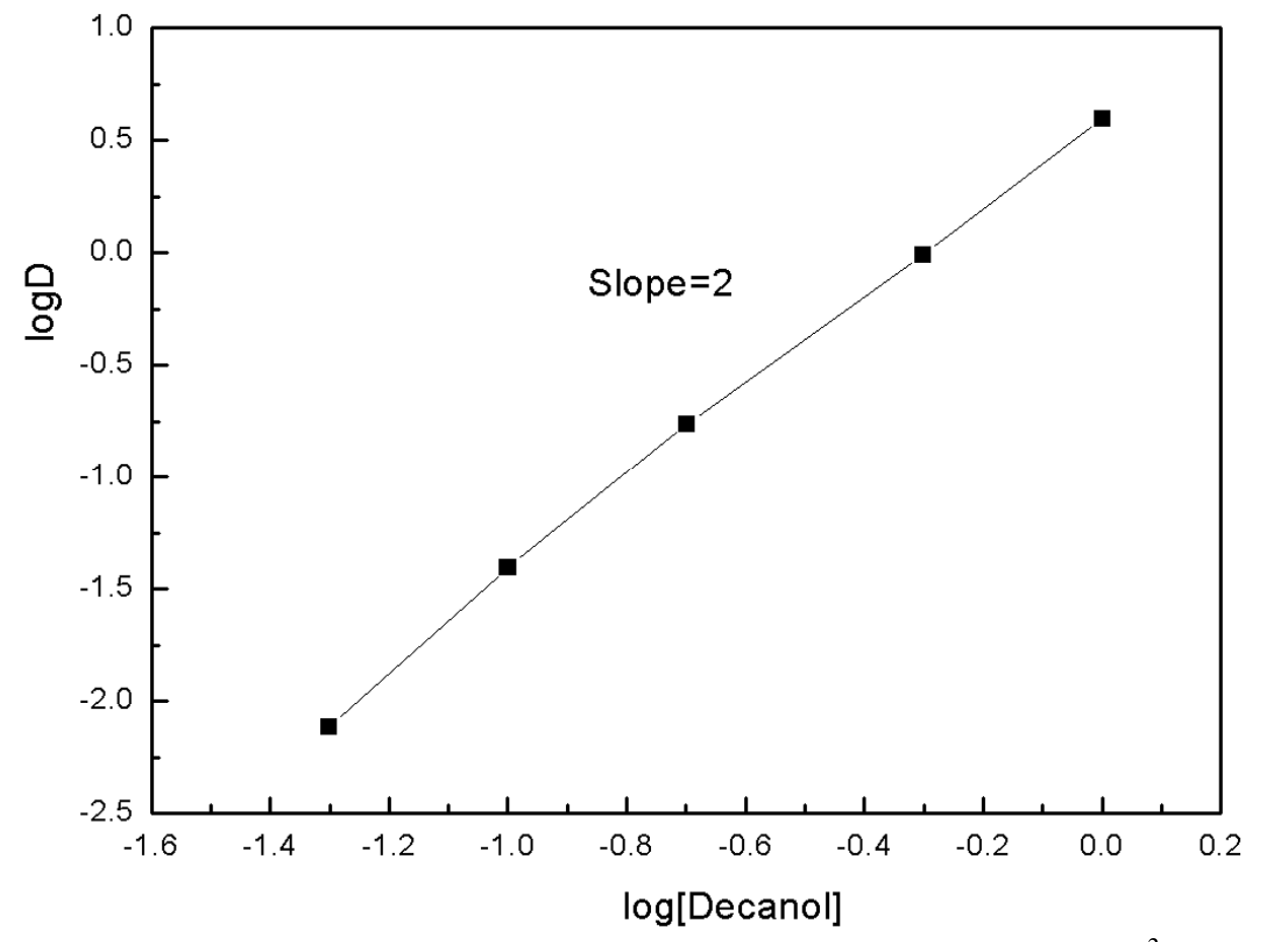

Fig. 1 Effect of decanol concentration on the extraction of iron (III) $\left(0.1 \mathrm{~mol} . \mathrm{dm}^{-3}\right)$ from $8 \mathrm{~mol} . \mathrm{dm}^{-3}$ hydrochloric acid solutions.

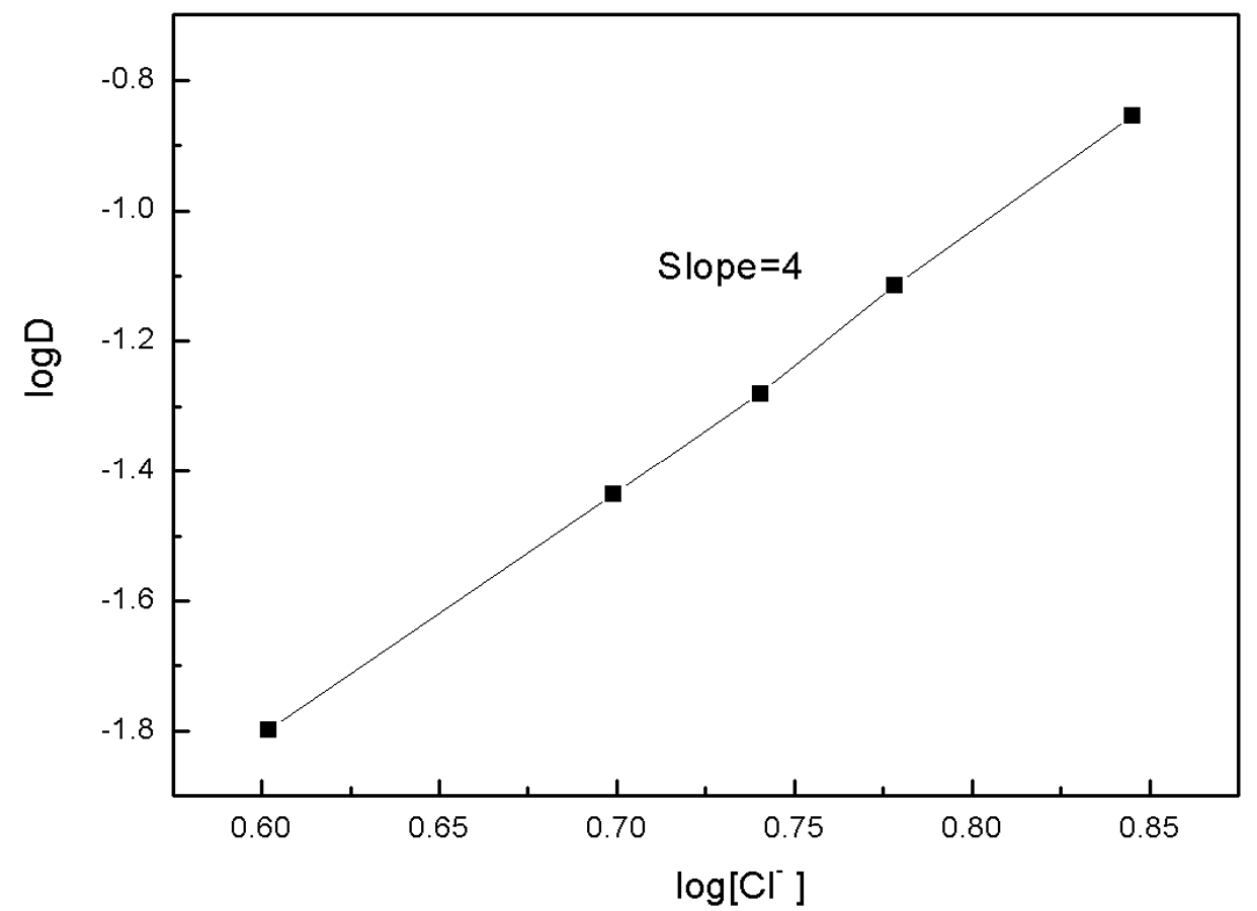

Fig. 2 Effect of chloride ion concentration on the extraction iron (III) $\left(0.1 \mathrm{~mol} . \mathrm{dm}^{-3}\right)$ at constant hydrogen ion concentration $\left(4 \mathrm{~mol} \cdot \mathrm{dm}^{-3}\right)$, [decanol $]=0.86 \mathrm{~mol} \cdot \mathrm{dm}^{-3}$. 


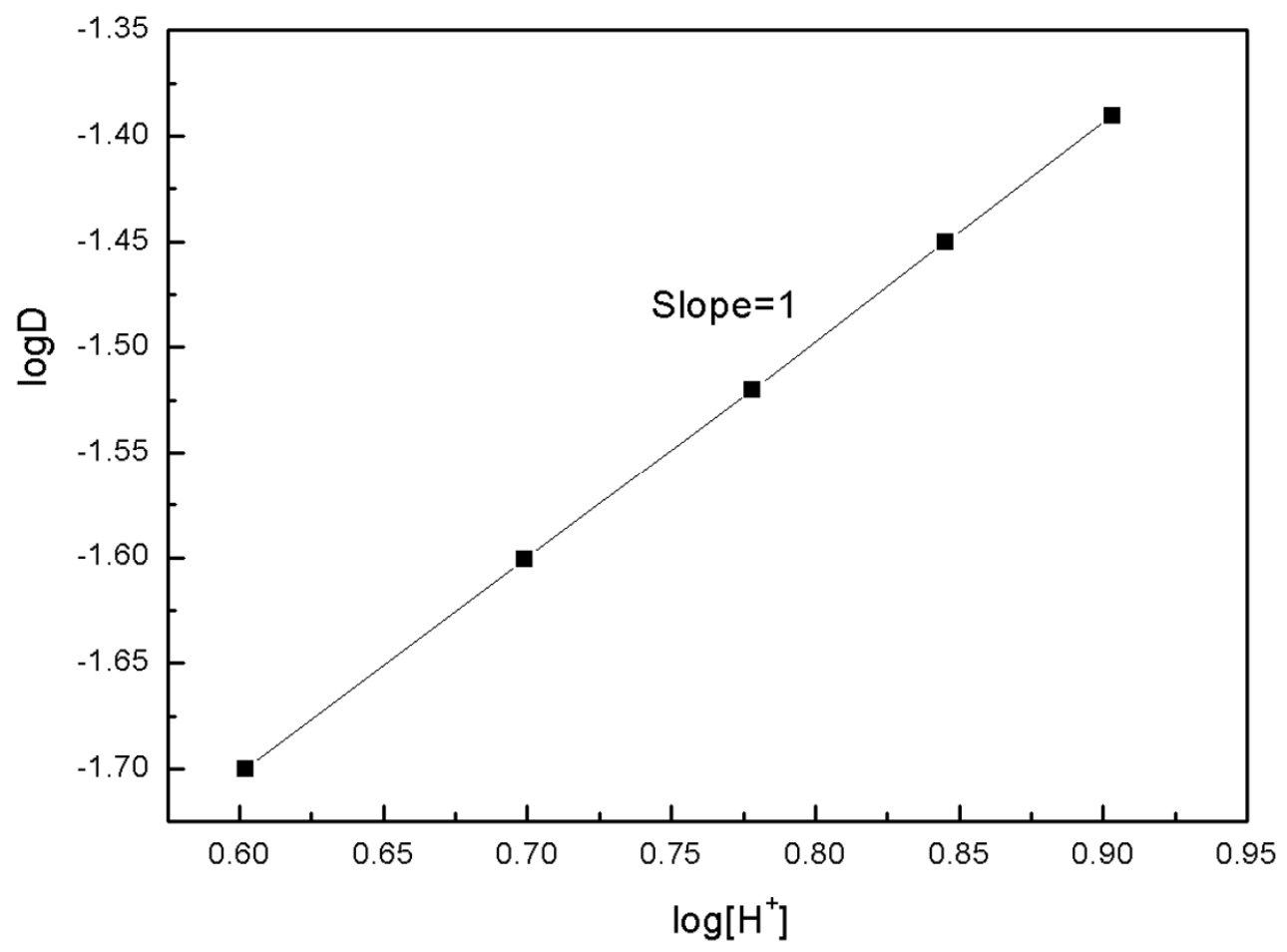

Fig. 3 Effect of hydrogen ion concentration on the extraction of iron (III) $\left(0.1 \mathrm{~mol}^{-3} \mathrm{dm}^{-3}\right)$ at constant chloride ion concentration $\left(8 \mathrm{~mol} . \mathrm{dm}^{-3}\right)$, [decanol $]=0.86 \mathrm{~mol} . \mathrm{dm}^{-3}$.

Based on the preceding studies the extraction equilibria of iron (III) with decanol in kerosene can be expressed as Equa. 1.

$$
\mathrm{H}^{+}{ }_{a q}+\mathrm{Fe}^{3+}{ }_{a q}+4 \mathrm{Cl}^{-}{ }_{a q}+2 \mathrm{~A}_{\text {org }}=\mathrm{HFeCl}_{4} \cdot 2 \mathrm{~A}_{\text {org }}
$$

\section{A- decanol}

\section{Effect of phase contact time}

Iron (III) was contacted with $0.86 \mathrm{~mol} \mathrm{dm}^{-3}$ decanol in kerosene for 1-20 min. Quantitative extraction of iron (III) by decanol was found within $5 \mathrm{~min}$. There was no adverse effect on the extraction yield up to $20 \mathrm{~min}$ (Fig 4). From the result, it was found that the extraction of iron (III) by decanol from hydrochloric acid solutions is a quick process, applicable to industrial applications. 


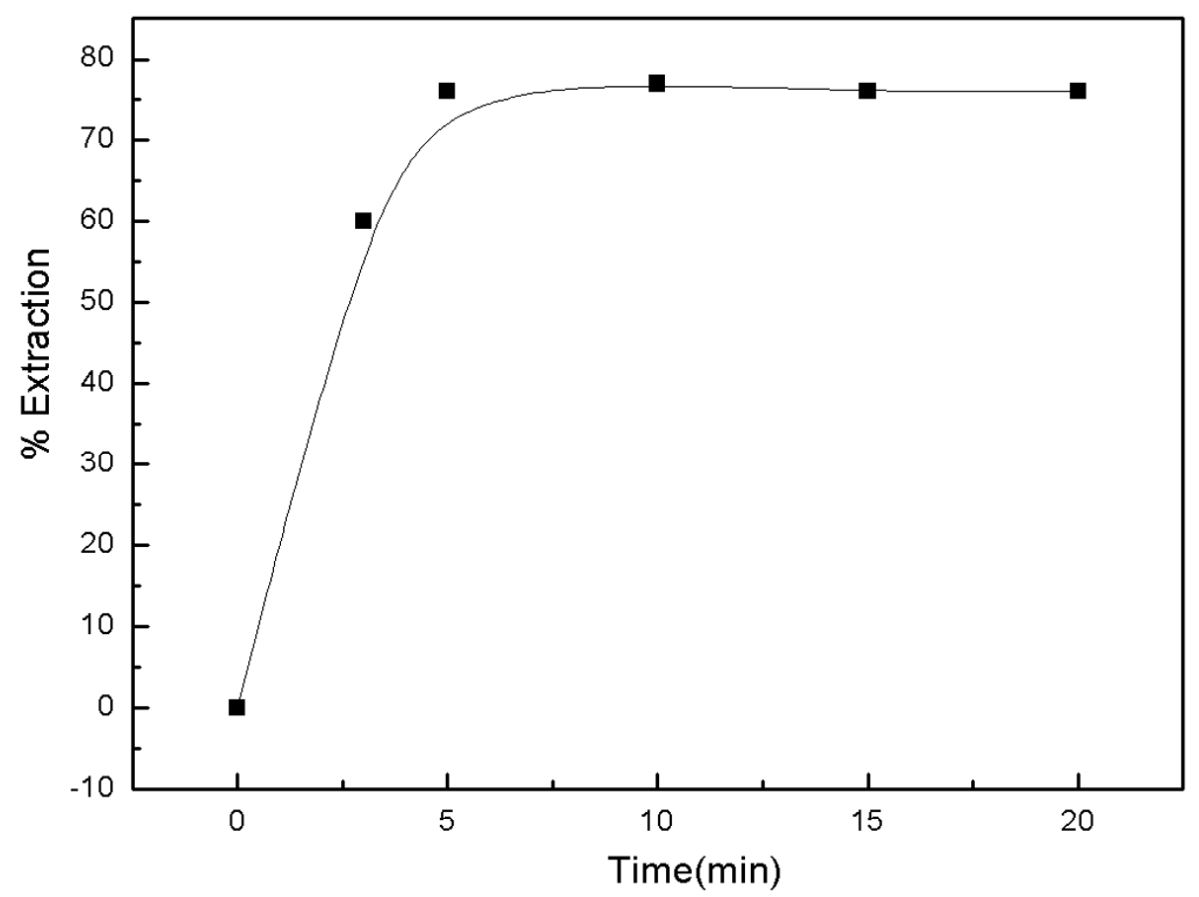

Fig. 4 Dependence of extraction rate on contact time. $\left[\mathrm{Fe}^{3+}\right]=0.1 \mathrm{~mol} . \mathrm{dm}^{-3}$, [decanol $]=0.86$ mol. $\mathrm{dm}^{-3},[\mathrm{HCl}]=8 \mathrm{~mol} \cdot \mathrm{dm}^{-3}$.

\section{IR spectra of the extracted complexes of iron (III)}

The IR spectra of the extracted complexes showed that the stretching frequency of O-H was shifted from $3334 \mathrm{~cm}^{-1}$ in decanol to $3523 \mathrm{~cm}^{-1}$ in $\mathrm{FeCl}_{4} \cdot 2$ Decanol. The stretching frequency of C-O was shifted from $1049 \mathrm{~cm}^{-1}$ in decanol to $1051 \mathrm{~cm}^{-1}$ in $\mathrm{FeCl}_{4} \cdot 2$ Decanol. These changes indicate the possibility of bonding between Fe and decanol.

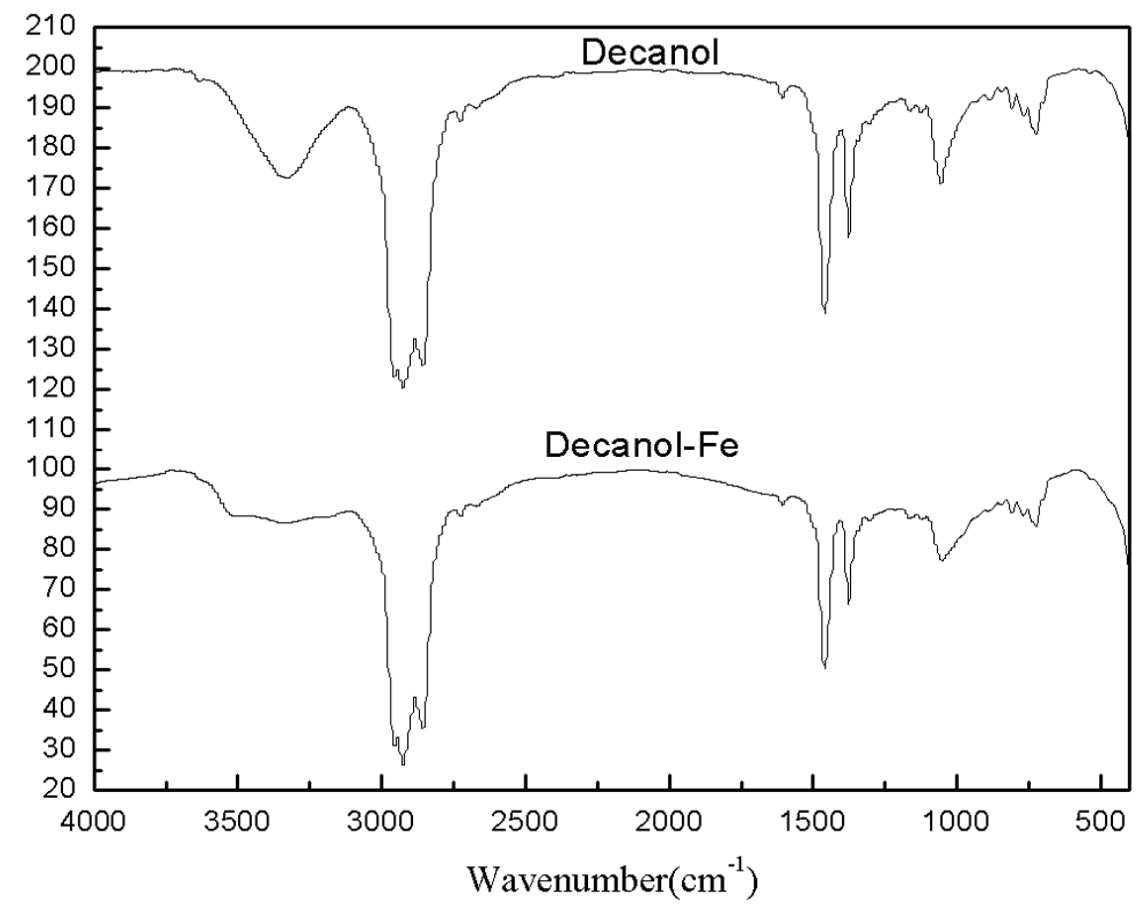

Fig. 5 IR spectra of Decanol and Decanol-Fe.

\section{Extraction behavior of other metal ions}

The extraction behavior of other associated metal ions, namely, titanium (IV ) aluminum (III), calcium (II) and magnesium (II), was studied in $8 \mathrm{~mol} \mathrm{dm}^{-3}$ hydrochloric acid solutions using 0.86 mol dm${ }^{-3}$ decanol in kerosene as extractant, which often exist along with iron (III) in hydrochloric 
acid leaching solutions of titanium mineral. It was found that titanium (IV ) aluminum (III), calcium (II) and magnesium (II) were not extracted under these experimental conditions. Namely iron (III) can be separated from the associated metal ions through the extraction process.

\section{Iron (III) stripping}

The stripping behavior of iron (III) has been investigated using hydrochloric acid as the stripping agent. Fig. 6 showed that as the decrease of hydrochloric acid concentration the stripping rate increased. With $0 \sim 1.0 \mathrm{~mol} \mathrm{dm}^{-3}$ hydrochloric acid as the stripping agents, the stripping rate of iron (III) was above $90 \%$. It is clear that iron (III) is easy to be stripped from the extraction complexes.

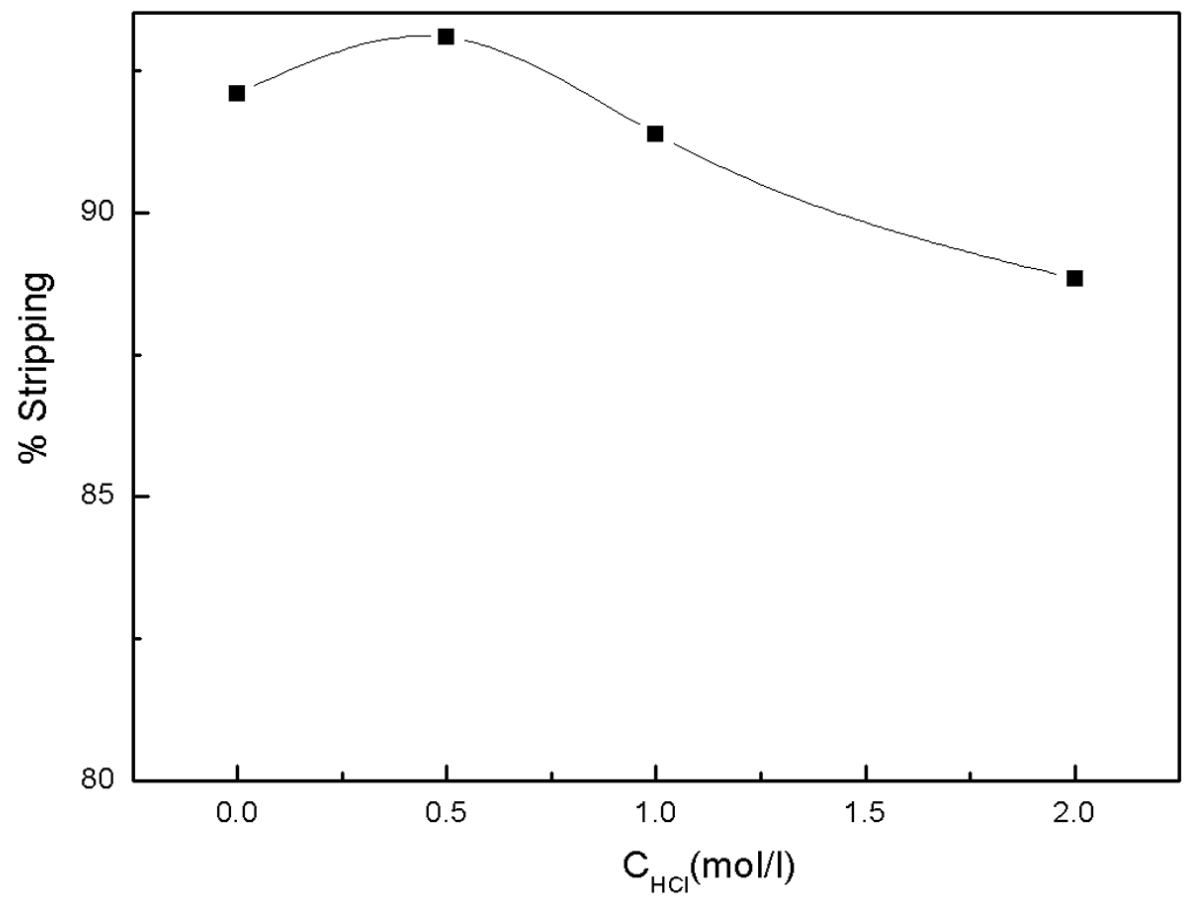

Fig. 6 Stripping behavior of iron (III) from loaded decanol phase using $\mathrm{HCl}$.

\section{Conclusions}

Decanol is effective and selective for the extraction of iron (III) in acidic chloride solutions. The extraction equilibrium equation was inferred. And that extracted iron(III) is easy to be stripped. Therefore decanol is suitable for the extraction of iron (III) in acidic chloride solutions.

\section{References}

[1] T. Hirato, Z.-C. Wu, Y. Yamada, H. Majima, Improvement of the stripping characteristics of Fe(III) utilizing a mixture of di (2-ethylhexyl) phosphoric acid and tri-n-butyl phosphate, Hydrometallurgy 28 (1992) 81-93.

[2] F. Islam, H. Rahman, M. Ali, Solvent extraction separation study of Ti(IV) Fe(III) and Fe(II) from aqueous solutions with di-2-ethyl hexyl phosphoric acid in benzene, J. Inorg. Nucl. Chem. 41 (1979) 217-221.

[3] R. Kimura, P. Haunschild, K. Liddell, A mathematical model for calculation of equilibrium solution speciations for the $\mathrm{FeCl} 3-\mathrm{FeCl} 2-\mathrm{CuCl} 2-\mathrm{CuCl}-\mathrm{HCl}-\mathrm{NaCl}-\mathrm{H} 2 \mathrm{O}$ system at $25^{\circ} \mathrm{C}$, Mater. Trans. B 15 (1984) 213-219.

[4] N. Miralles, A.M. Sastre, E. Figuerola, M. Martinez, Solvent extraction of iron (III) by bis (2,4,4-trimethylpentyl) phosphinic acid: experimental equilibrium study, Hydrometallurgy 31 (1992) 1-12. 
[5] J.W. Roddy, C.F. Coleman, S. Arai, Mechanism of the slow extraction of iron(III) from acid perchlorate solutions by di(2-ethylhexyl)phosphoric acid in n-octane, J. Inorg. Nucl. Chem. 33 (1971) 1099-1118.

[6] T. Sato, T. Nakamura, M. Ikeno, The extraction of iron(III) from aqueous acid solutions by di(2-ethylhexyl)phosphoric acid , Hydrometallurgy 15 (1985) 209-217.

[7] C. Suárez, E. Ahumada, F. Orellana, H. Hein, G. Cote, H. Lizama, Extraction of iron(III) from acidic sulfate solutions with bis(2-ethylhexyl)phosphoric acid in PENRECO® 170 ES, a new friendly diluent, J. Chem. Technol. Biotechnol. 77 (2002) 183-189.

[8] V.V. Bagreev, C. Fischer, L.M. Yudushkina, Y.A. Zolotov, Mutual influence of metals in the extraction of their chloride complexes with tri-n-octylamine and aliquat 336 in benzene, J. Inorg. Nucl. Chem. 40 (1978) 553-557.

[9] R.K. Mishra, P.C. Rout, K. Sarangi, K.C. Nathsarma, Solvent extraction of Fe(III) from the chloride leach liquor of low grade iron ore tailings using Aliquat 336, Hydrometallurgy 108 (2011) 93-99.

[10] W. Smuek, S. Siekierski, The influence of diluent on the extraction of iron(III) from hydrochloric acid solutions by tertiary amines, J. Inorg. Nucl. Chem. 24 (1962) 1651-1666.

[11] S. Yu, J. Chen, C.-Y. Chen, Synergistic extraction of ferric iron in sulfate solutions by tertiary amine and 2-ethylhexyl 2-ethylhexylphosphonic acid (HEHEHP) or dialkylphosphonic acid, Hydrometallurgy 22 (1989) 183-192.

[12] S.I. El Dessouky, Y.A. El-Nadi, I.M. Ahmed, E.A. Saad, J.A. Daoud, Solvent extraction separation of $\mathrm{Zn}(\mathrm{II}), \mathrm{Fe}(\mathrm{II}), \mathrm{Fe}(\mathrm{III})$ and $\mathrm{Cd}(\mathrm{II})$ using tributylphosphate and CYANEX 921 in kerosene from chloride medium, Chem. Eng. Prog. 47 (2008) 177-183.

[13] R.K. Mishra, P.C. Rout, K. Sarangi, K.C. Nathsarma, A comparative study on extraction of $\mathrm{Fe}(\mathrm{III})$ from chloride leach liquor using TBP, Cyanex 921 and Cyanex 923, Hydrometallurgy 104 (2010) 298-303.

[14] J. Saji, T.P. Rao, C.S.P. Iyer, M.L.P. Reddy, Extraction of iron(III) from acidic chloride solutions by Cyanex 923, Hydrometallurgy 49 (1998) 289-296.

[15] W. Sanad, H. Flex, A. Haggag, Kinetics of iron(III) chloride extraction with n-tributyl phosphate, J. Radioanal. Nucl. Ch. 75 (1982) 121-128.

[16] M. Miroslav, S. Jana, C. Miroslav, C. Jiri, Effect of the solvent on the extraction of iron(III)chloride by tri-n-octylamine, Chemicky Prumysl, 28 (1978) 16-23.

[17] M. Liu, Y.M. Zhou, Removal of Fe (III) from sulphate solutions by synergistic extraction using N235-TBP mixed solvent systems, Chin. J. Nonferr. Met. 15 (2005) 1648-1654.

[18] X.X. Zhou, X.N. Du, T. Zhu, Solvent Extractive Separation of Cobalt (II) and Iron (II) with Tertiary A`mine, Chin. J. Proc. Eng., 1(2001), 360-364. 